Check for updates

Cite this: RSC Adv., 2018, 8, 41575

Received 14th November 2018 Accepted 30th November 2018

DOI: $10.1039 / c 8 \mathrm{ra09383k}$

rsc.li/rsc-advances

\section{A first-principles calculation of structural,
mechanical, thermodynamic and electronic \\ A first-principles calculation of structural,
mechanical, thermodynamic and electronic properties of binary $\mathrm{Ni}-\mathrm{Y}$ compounds}

\author{
YunXuan Zhou, (DD ${ }^{a}$ MingYu Hu, (D) ${ }^{a}$ Pei Yan, ${ }^{a}$ Xiaoli Shi, ${ }^{a}$ XiaoYu Chong ${ }^{\star b}$ \\ and Jing Feng*a
}

\begin{abstract}
The intermetallic compounds between rare earth (RE) elements and transition metal elements have been comprehensively researched due to their appealing magnetic, electronic, optical and thermal properties, in which $\mathrm{Ni}-\mathrm{Y}$ alloys are one kind of important system. In this work, a systematic investigation concerned with structures, elastic, and thermodynamic properties of $\mathrm{Ni}_{17} \mathrm{Y}_{2}, \mathrm{Ni}_{5} \mathrm{Y}, \mathrm{Ni}_{7} \mathrm{Y}_{2}, \mathrm{Ni}_{3} \mathrm{Y}, \mathrm{Ni}_{2} \mathrm{Y}, \mathrm{NiY} \mathrm{Ni}_{2} \mathrm{Y}_{3}$ and $\mathrm{NiY}_{3}$ in $\mathrm{Ni}-\mathrm{Y}$ systems is implemented by means of first-principles calculations. NiY has the lowest formation enthalpy within $-0.49 \mathrm{~kJ}$ per mol per atom. $\mathrm{Ni}_{5} \mathrm{Y}$ has the largest bulk modulus, shear modulus and Young's modulus of $181.71 \mathrm{GPa}, 79.75 \mathrm{GPa}$ and $208.70 \mathrm{GPa}$, respectively. Furthermore, the effects of different concentrations of yttrium on the mechanical and thermal properties of $\mathrm{Ni}-\mathrm{Y}$ compounds are estimated by using the Voigt-Reuss method. The electronic density of states and chemical bonding between $\mathrm{Ni}$ and $\mathrm{Y}$ are key factors that determine mechanical and thermodynamic properties of these compounds. What's more, results indicate that all compounds are dynamically stable as shown by the calculated phonon dispersions.
\end{abstract}

\section{Introduction}

In the past few decades, the intermetallic compounds between transition metal elements and rare earth (RE) elements have been extensively researched due to their appealing magnetic, electronic, optical and thermal properties. Among Ni-RE systems, the Ni-Y system may be of particular interest for its extensive applications in magnetic, amorphous, catalytic materials and hydrogen storage materials. ${ }^{1-7}$ The magnetic properties of $\mathrm{Ni}-\mathrm{Y}$ compounds have attracted significant attention and been discussed by M. Shimizu et al. ${ }^{3}$ and J. Beille et $a .^{8} \mathrm{Ni}_{3} \mathrm{Y}$ showed very low ferromagnetism while $\mathrm{Ni}_{7} \mathrm{Y}_{2}$ demonstrated thermal spontaneous magnetization in their results. The thermodynamic stability of the $\mathrm{Ni}-\mathrm{Y}$ system and Co-Ni-Y system have been researched by Z. M. Du et al. ${ }^{\mathbf{9}, 10}$ who discussed $\mathrm{Ni}-\mathrm{Y}$ binary and $\mathrm{Co}-\mathrm{Ni}-\mathrm{Y}$ ternary phase diagrams. Moreover, $\mathrm{Al}-\mathrm{Ni}-\mathrm{Y}$ and $\mathrm{Mg}-\mathrm{Ni}-\mathrm{Y}$ alloys, as amorphous materials, indicating great forming abilities of metallic glass and excellent mechanical properties, have been reported by X. Y. Jiang et al. ${ }^{6}$ and Y. M. Soifer et al. ${ }^{7}$ Moreover, Ni and Y have been used as component elements for catalytic materials. The order of catalytic efficiency toward the hydrogenation reaction was $\mathrm{PtY}<\mathrm{NiY}<\mathrm{CoY}<\mathrm{PtNiY}<\mathrm{PtCoY}$ in El-Bahy's research. ${ }^{\mathbf{1 1}}$

${ }^{a}$ Faculty of Materials Science and Engineering, Kunming University of Science and Technology, Kunming, 650093, P. R. China.E-mail:jingfeng@kmust.edu.cn

${ }^{b}$ Department of Materials Science and Engineering, Pennsylvania State University, University Park, PA 16802, USA. E-mail: xuc83@psu.edu
Furthermore, Ni is a candidate device component which is used in thermoelectric (TE) devices due to its eminent electrical and thermal characteristics. ${ }^{12}$ It is well known that nickel-based superalloy is a commonly used superalloy, which is widely used in manufacturing aerospace engines, industrial gas turbine blades and other hot end components. M. A. Shevchenko et al. ${ }^{13}$ have researched thermodynamic properties of binary alloys including $\mathrm{Ni}-\mathrm{Sc}$ and $\mathrm{Ni}-\mathrm{Y}$ systems, they predicted the similar parameters of multicomponent systems and studied the amorphous tendency of alloys. S. Kardellass et al. ${ }^{\mathbf{1 4}}$ had been assessed the thermodynamically in Ni-Sc system using the CALPHAD approach. They calculated the Ni-Sc phase diagram using Kaptay model, which showed that the formation enthalpy of Ni-Sc compounds would be welcome to improve thermodynamic evaluation. The thermodynamic modeling of binary compounds, such as rare earth element $\mathrm{Yb}$ and transition element $\mathrm{Ni}$, was studied using the CALPHAD method in combination with first-principles calculations based on density functional theory (DFT) by $\mathrm{Hu}$ et al. ${ }^{15}$ Although the density of state of $\mathrm{Ni}_{3} \mathrm{Y}, \mathrm{Ni}_{5} \mathrm{Y}$, and $\mathrm{Ni}_{7} \mathrm{Y}_{2}$ have been calculated by $\mathrm{M}$. Shimizu et $a .^{3}$ and thermodynamics of Ni-Y alloys have been researched by $\mathrm{M}$. A. Shevchenko et $a .^{13}$ the electronic, mechanical and thermodynamics of Ni-Y alloys have not been systematically calculated in previous reports. In the present work, the formation enthalpy, electronic, mechanical and thermodynamic properties of the $\mathrm{Ni}-\mathrm{Y}$ compounds are predicted from first-principles calculations based on the density functional theory (DFT), to guide the experiments in the future. 


\section{Computational method and details}

According to the Ni-Y binary phase diagram ${ }^{16}$ in Fig. 1 , the structures of Ni-Y compounds with different stoichiometry can be acquired: $\mathrm{Ni}_{17} \mathrm{Y}_{2}$ with a hexagonal structure $\left(\mathrm{PG}_{3} / \mathrm{mmc}\right.$, no. 194); $\mathrm{Ni}_{5} \mathrm{Y}$ with a hexagonal structure $(P 6 / \mathrm{mmm}$, no. 191$) ; \mathrm{Ni}_{7} \mathrm{Y}_{2}$ with a rhombohedral structure $(R \overline{3} m H$, no. 166$) ; \mathrm{Ni}_{3} \mathrm{Y}$ with a rhombohedral structure $(R \overline{3} m H$, no. 166$) ; \mathrm{Ni}_{2} \mathrm{Y}$ with a cubic structure $(F d \overline{3} m S$, no. 227); NiY with a orthorhombic structure (Pnma, no. 62); $\mathrm{Ni}_{2} \mathrm{Y}_{3}$ with a tetragonal structure $\left(P 4_{1} 2_{1} 2\right.$, no. 92); and the $\mathrm{NiY}_{3}$ with an orthorhombic structure (Pnma, no. 62).

In this paper, all the calculations including total energy, elastic properties, electronic structures and thermodynamic properties carried by using a first-principles calculation based on the density functional theory (DTF), as implemented in the Cambridge Serial Total Energy Package (CASTEP) code. ${ }^{17}$ To estimate the calculated, the generalized gradient approximation (GGA) in Perdew-Burke-Ernzerhof for surfaces and solids (PBEsol) is employed as the exchange-correlation function. ${ }^{18}$ Plane wave cutoff energy is chosen as $500 \mathrm{eV}$ to convergence for all the calculations. The Brillouin zone (BZ) is performed by using the $k$-point meshes with $5 \times 5 \times 5$ grids according to the Monkhorst-Pack method. To describe the electronic function, the ultra-soft pseudopotentials (USPPs) ${ }^{19}$ of Vanderbilt-type are carried out and the valence electron configurations for $\mathrm{Ni}$ and $\mathrm{Y}$ atoms are $3 \mathrm{~d}^{8} 4 \mathrm{~s}^{2}$ and $4 \mathrm{~d}^{1} 5 \mathrm{~s}^{2}$, respectively. During the structural optimization, Broydene Fletchere Goldarde Shanno (BFGS) method is used until the total energy changes are converged to 1 $\times 10^{-9} \mathrm{eV}$ per atom, self-consistent field convergence to $2 \times$ $10^{-6} \mathrm{eV}$ per atom, maximum force $0.03 \mathrm{eV} \AA^{-1}$, respectively. Elastic constants of a solid are calculated by an efficient strainstress method through a linear least-square fit of first-principles calculation results. And the phonon dispersion curves of $\mathrm{Ni}-\mathrm{Y}$ compounds are calculated according to the finite displace method implanted in CASTEP. This method is to construct a supercell, move the atom, and calculate the force of all the atoms in the cell. A force constant matrix was constructed based

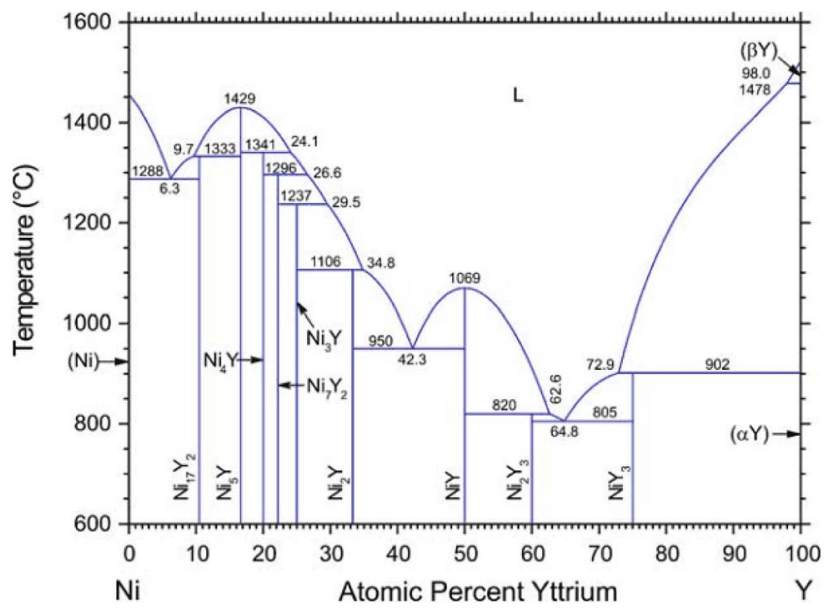

Fig. 1 The Ni-Y Phase diagram by Mattern N., Zinkevich M., Löser W. et al. in ref. 16 . on this force. What's more, this method determines the dynamical matrix starting from following equation: $f_{\mathrm{s}}=-\Phi_{\mathrm{st}} u_{\mathrm{t}}$, where $f_{\mathrm{s}}, \Phi_{\mathrm{st}}$ and $u_{\mathrm{t}}$ represent force, force constant matrix and the displacement, respectively. The cut-off radius of the finite displace method is $5.0 \AA$.

The negative values of formation enthalpy ${ }^{20,21}$ indicate that the thermodynamically stability of compounds which can be estimated by the following expressions:

$$
\Delta H_{\mathrm{r}}\left(\mathrm{Ni}_{x} \mathrm{Y}_{y}\right)=\frac{E_{\text {tot }}\left(\mathrm{Ni}_{x} \mathrm{Y}_{y}\right)-x E_{\text {bin }}(\mathrm{Ni})-y E_{\text {bin }}(\mathrm{Y})}{x+y}
$$

where $\Delta H_{\mathrm{r}}\left(\mathrm{Ni}_{x} \mathrm{Y}_{y}\right)$ is the formation enthalpy of $\mathrm{Ni}_{x} \mathrm{Y}_{y}$ per atom, $E_{\text {tot }}\left(\mathrm{Ni}_{x} \mathrm{Y}_{y}\right)$ is the total energy of $\mathrm{Ni}_{x} \mathrm{Y}_{y}$ phase; $E_{\mathrm{bin}}$ is the cohesive energy of pure Ni and $\mathrm{Y}$ crystals, respectively. The optimized crystal structures are illustrated in Fig. 2.

\section{Result and discussion}

\subsection{Equilibrium lattice constants and phonon}

The calculated crystal structures of the Ni-Y compounds are listed in Table 1, which are compared with the experimental results from other references. ${ }^{1,2,4,5}$ From Table 1 , we can clearly see that the calculated values are in good agreement with the other theoretical values. The error range of the lattice parameter is within $2 \%$. What's more, the error of $\mathrm{Ni}_{3} \mathrm{Y}$ between calculated lattice constants and the experimental lattice constants is very small. It is important to note that the effect of temperature on crystal structure and lattice defects can lead to small discrepancies. In our work, the calculated lattice parameters via using PBEsol functional are a little different from the results obtained from other methods. ${ }^{22}$ On the other hand, the obtained density of $\mathrm{Ni}-\mathrm{Y}$ compounds decreases with increasing $\mathrm{Y}$ concentration because the density of the $\mathrm{Y}$ atom is larger than that of the $\mathrm{Ni}$ atom. $\mathrm{Ni}_{17} \mathrm{Y}_{2}$ has the largest density with the value of $7.97 \mathrm{~g} \mathrm{~cm}^{-3}$, while the $\mathrm{NiY}_{3}$ has the minimum values of $4.93 \mathrm{~g} \mathrm{~cm}^{-3}$.

The calculated phonon dispersion curves of Ni-Y compounds are shown in Fig. 3. In these Ni-Y compounds, the long range of the Coulomb interactions should lead to the frequencies of longitudinal optical (LO) modes above those of transversal optical (TO) modes. The calculated phonon dispersion curves show no soft modes at any high-symmetry dispersion, suggesting that those compounds are dynamic stable. ${ }^{23}$ Moreover, the phonon density of state for $\mathrm{Ni}-\mathrm{Y}$ compounds are shown in Fig. 3, which demonstrates the frequency vibrations are lower than $0.5 \mathrm{THz}$ due to the motion of yttrium element.

\subsection{Thermodynamic stability}

The calculated lattice parameters, density, volume, and formation enthalpy of Ni-Y compounds are shown in Table 1 . As we know that the structural stability of a material is dominated by many factors that including the chemical bonding, structural type and localized hybridization. The stability of the Ni-Y compounds can be estimated by their formation enthalpies. What's more, the lower the enthalpy is, the more stable the material is. From Fig. 4, the calculated formation enthalpy of 


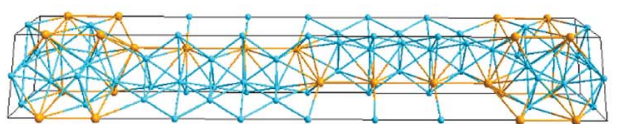

$\mathrm{Ni}_{7} \mathrm{Y}_{2}$

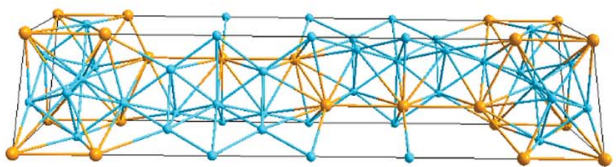

$\mathrm{Ni}_{2} \mathrm{Y}_{3}$
$\mathrm{Ni}_{3} \mathrm{Y}$

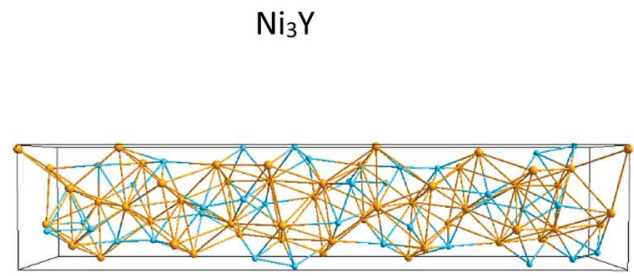

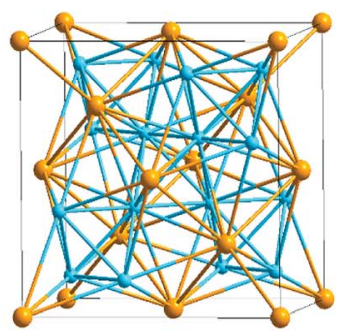

$\mathrm{Ni}_{2} \mathrm{Y}$

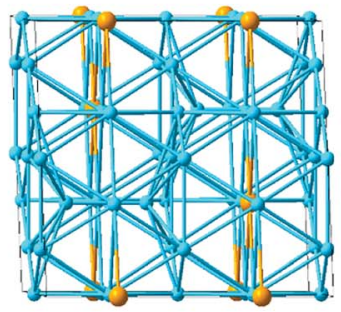

$\mathrm{Ni}_{17} \mathrm{Y}_{2}$

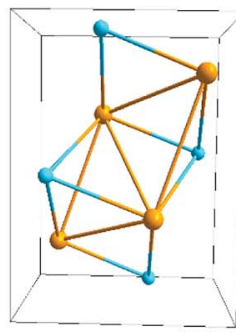

NiY

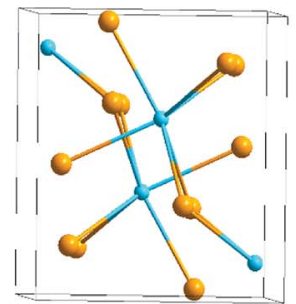

$\mathrm{NiY}_{3}$

Fig. 2 The crystal structure of $\mathrm{Ni}-\mathrm{Y}$ compounds. Sky blue and light orange spheres represent the $\mathrm{Ni}$ and $\mathrm{Y}$ atoms, respectively.

$\mathrm{Ni}-\mathrm{Y}$ compounds is negative values. All compounds are lying on the convex hull, implying that these structures are thermodynamically stable at the ground state. It is noted that, in the Ni-Y compounds, the NiY has the lowest formation enthalpy is $-0.494 \mathrm{eV}$ per atom. The stability order of $\mathrm{Ni}-\mathrm{Y}$ compounds forms the following this sequence: $\mathrm{NiY}>\mathrm{Ni}_{2} \mathrm{Y}>\mathrm{Ni}_{3} \mathrm{Y}>\mathrm{Ni}_{7} \mathrm{Y}_{2}>$ $\mathrm{Ni}_{5} \mathrm{Y}>\mathrm{Ni}_{2} \mathrm{Y}_{3}>\mathrm{Ni}_{17} \mathrm{Y}_{2}>\mathrm{NiY}_{3}$.

According to the phonon properties calculated within Density-Functional Perturbation Theory (DFPT), the associated thermodynamic properties of Ni-Y systems can be got by the following formula. ${ }^{24}$ The free energy of the system $(F(T))$ can be used following expression:

$$
F(T)=E_{\text {zero-point }}+k_{\mathrm{B}} T \int \ln \left(1-\exp \left(\frac{h \omega}{k_{\mathrm{B}} T}\right)\right) F(\omega) \mathrm{d} \omega
$$

where $E_{\text {total }}, k_{\mathrm{B}}, h$, and $\omega$ represent the static total energy, the Boltzmann constant, the reduced Plank constant and the phonon frequency, respectively; $E_{\text {zero-point }}$ is the zero-point vibrational energy, which is expressed as:

$$
E_{\text {zero-point }}=\frac{1}{2} \int F(\omega) h \omega \mathrm{d} \omega
$$

where $F(\omega)$ is the phonon density of states. Furthermore, the formation enthalpy depends on temperature, which can be

Table 1 Lattice constant, volume, formation enthalpy $\left(\Delta H_{r}\right)$ of $\mathrm{Ni}-\mathrm{Y}$ compounds accompanied with the available theoretical (DFT calculations) and experimental values

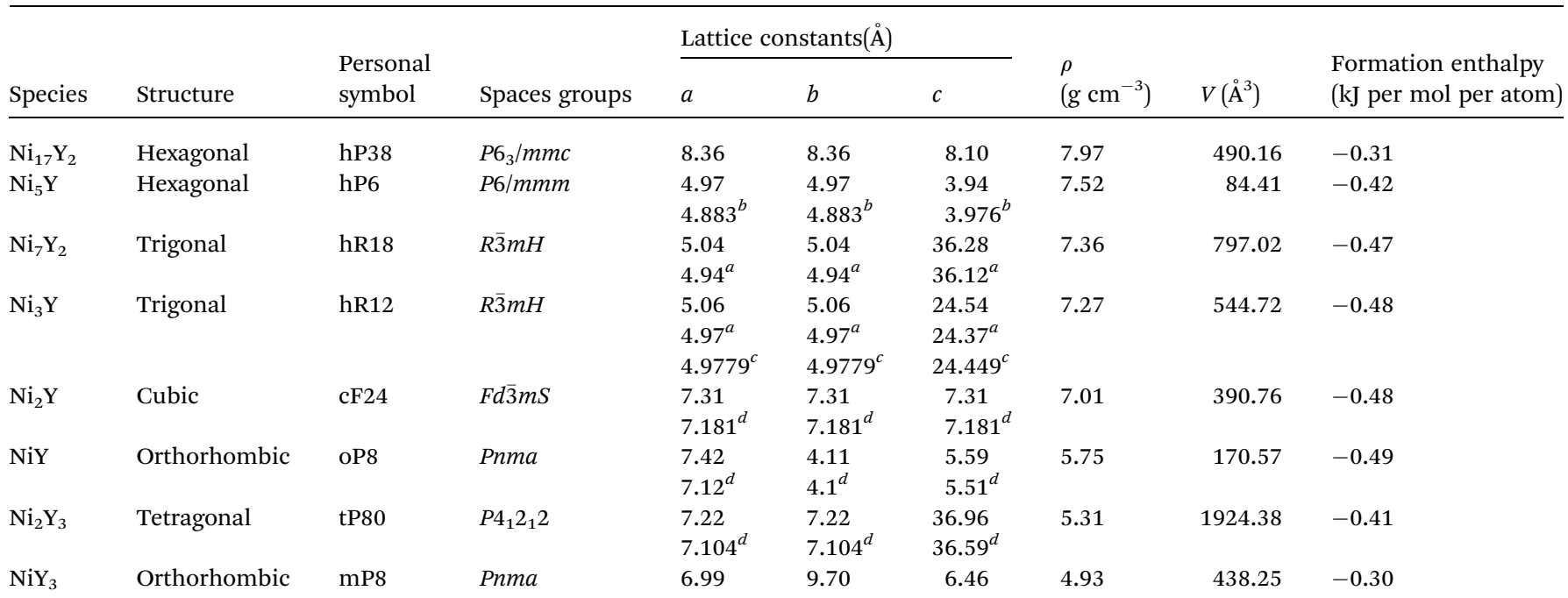

${ }^{a}$ Exp. in ref. $1{ }^{b}$ Exp. in ref. $4 .{ }^{c}$ Exp. in ref. $3{ }^{d}$ Exp. in ref. 2. 

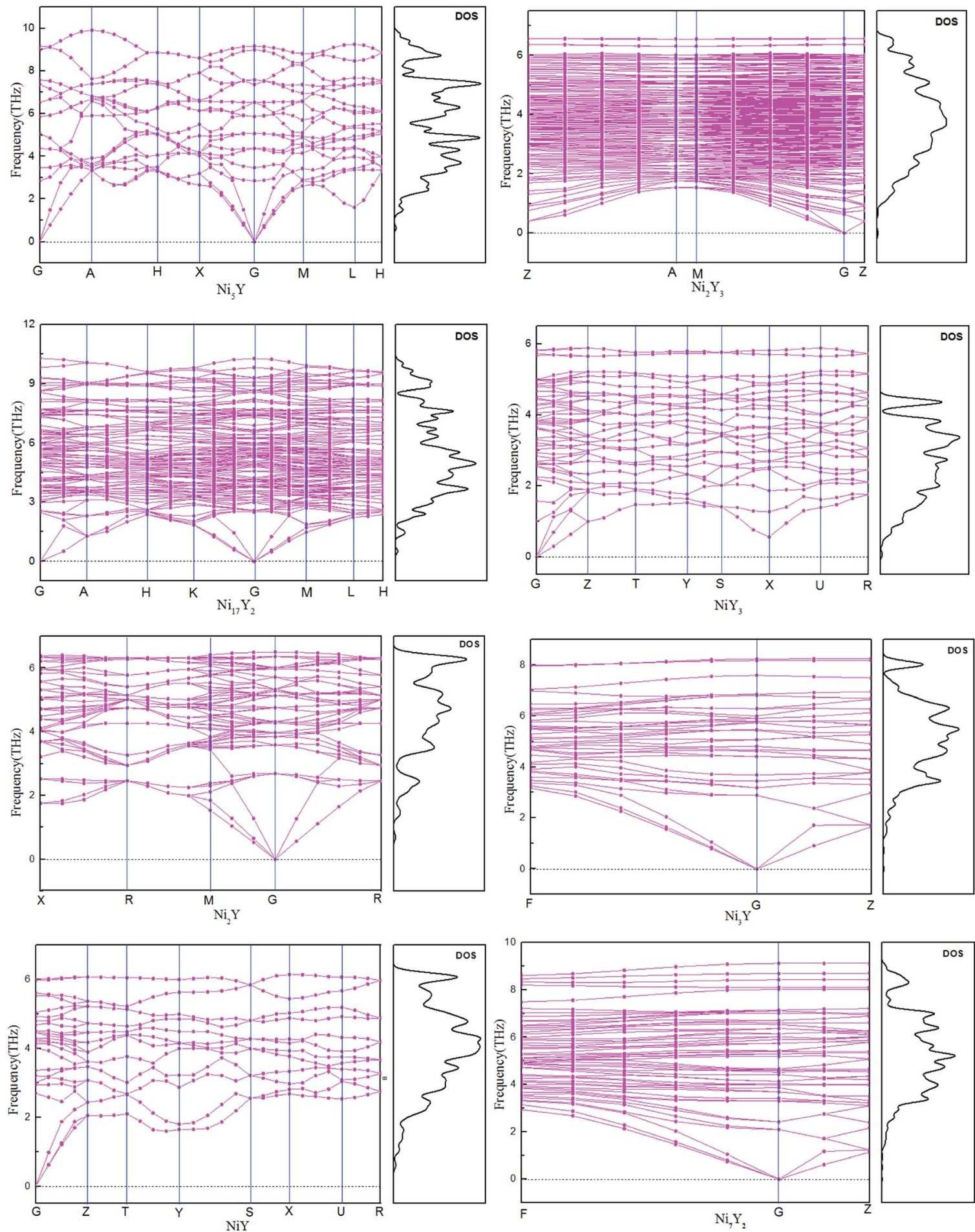

Fig. 3 The calculated phonon dispersion curves and phonon density of states of $\mathrm{Ni}-\mathrm{Y}$ compounds.

calculated by the formation enthalpy at $0 \mathrm{~K}$ and phonon contribution to the formation enthalpy as follows:

$$
H(T)=\int \frac{h \omega}{\exp \left(h \omega / k_{\mathrm{B}} T-1\right)} F(\omega) \mathrm{d}(\omega)
$$

Furthermore, the vibrational entropy and isochoric heat capacity can be calculated by:

$$
\begin{gathered}
S(T)=k_{\mathrm{B}}\left[\int \frac{h \omega / k_{\mathrm{B}} T}{\exp \left(h \omega / k_{\mathrm{B}} T\right)-1} F(\omega) \mathrm{d} \omega-\int F(\omega)\right. \\
\left.\left(1-\exp \left(\frac{h \omega}{k_{\mathrm{B}} T}\right)\right) \mathrm{d} \omega\right]
\end{gathered}
$$




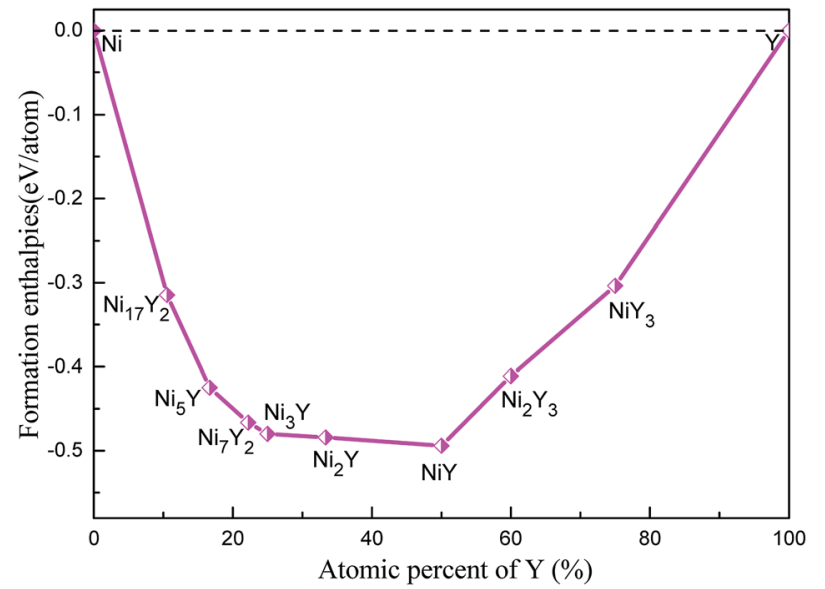

Fig. 4 The calculated formation enthalpy of $\mathrm{Ni}-\mathrm{Y}$ compounds as a function of $Y$ concentration.

$$
C_{\mathrm{V}}(T)=k_{\mathrm{B}} \int \frac{\left(h \omega / k_{\mathrm{B}} T\right)^{2} \exp \left(h \omega / k_{\mathrm{B}} T\right)}{\left[\exp \left(h \omega / k_{\mathrm{B}} T\right)-1\right]^{2}} F(\omega) \mathrm{d} \omega
$$

Fig. 5 shows the predicted thermodynamics of $\mathrm{Ni}-\mathrm{Y}$ compounds as a function of temperature: (a) enthalpy; (b) Gibbs free energy; (c) entropy; (d) Debye temperature; (e) the isochoric heat capacity of $\mathrm{Ni}-\mathrm{Y}$ compounds. It can be clearly seen that the enthalpy and entropy increase with the increasing temperature, while the Gibbs free energy decreases in the Ni-Y system. In Fig. 5, the thermodynamic stability of $\mathrm{NiY}_{3}$ is increased with the $S$ value becomes higher. The formation enthalpy increases linearly when the temperature is in the range from $200 \mathrm{~K}$ up to 1500 K. From Fig. 5, we know that the heat capacity increases very rapidly when the temperature is below $500 \mathrm{~K}$, and then approaches to a constant based on Dulong-Petit's law: $3 n R$, where $n$ and $R$ are the total number of atoms per formula and the gas constant, respectively. The heat capacity of $\mathrm{Ni}_{3} \mathrm{Y}$ and $\mathrm{Ni}_{7} \mathrm{Y}_{2}$ is lower than other compounds in Ni-Y system. What's more, at low temperature, the specific heat capacity of $\mathrm{Ni}-\mathrm{Y}$ compounds forms the following sequence: $\mathrm{Ni}_{5} \mathrm{Y}<\mathrm{Ni}_{7} \mathrm{Y}_{2}<\mathrm{Ni}_{3} \mathrm{Y}<$ $\mathrm{Ni}_{17} \mathrm{Y}_{2}<\mathrm{Ni}_{2} \mathrm{Y}<\mathrm{NiY}<\mathrm{Ni}_{2} \mathrm{Y}_{3}<\mathrm{NiY}_{3}$.

In Fig. 5, the Gibbs free energy is calculated by using the temperature-dependent formation enthalpy and entropy at $0 \mathrm{~K}$. As we know that the lattice stability can be described by the Debye temperature. The higher the Debye temperature is, the stronger the lattice stability is. ${ }^{25}$ The calculated Debye temperatures of $\mathrm{Ni}-\mathrm{Y}$ compounds are shown in Fig. 5, the similar trend can be seen for the Debye temperature of $\mathrm{Ni}-\mathrm{Y}$ compounds except for $\mathrm{Ni}_{2} \mathrm{Y}_{3}$ which increases with the varied temperature from $300 \mathrm{~K}$ to $1500 \mathrm{~K}$. What's more, the $\mathrm{Ni}_{17} \mathrm{Y}_{2}$ has the highest Debye temperature while $\mathrm{NiY}_{3}$ has the smallest Debye temperature due to different crystal structure and stoichiometric.

\subsection{Elastic constants and polycrystalline modulus}

The elastic stiffness tensor elements $C_{i j}$ of the Ni-Y compounds are calculated via first principle calculations with the stressstrain method based on the Hook's law. ${ }^{26}$ These results are summarized in Table 2. The elastic stiffness tensor is the fundamental mechanical property, which is very beneficial to understand the mechanical properties of the $\mathrm{Ni}-\mathrm{Y}$ phases.

The $C_{11}, C_{22}$, and $C_{33}$ of cubic $\mathrm{Ni}_{2} \mathrm{Y}$ are similar due to the symmetry of the crystal structure. $C_{11}, C_{22}$, and $C_{33}$ represent the uniaxial stress along the [100], [010], [001] direction, respectively. While $C_{44}, C_{55}$, and $C_{66}$ indicate the shearing strength at (100), (010) and (001) crystal plane, respectively. $C_{12}$ represents resist shear deformation at (100) crystal plane along the [110]
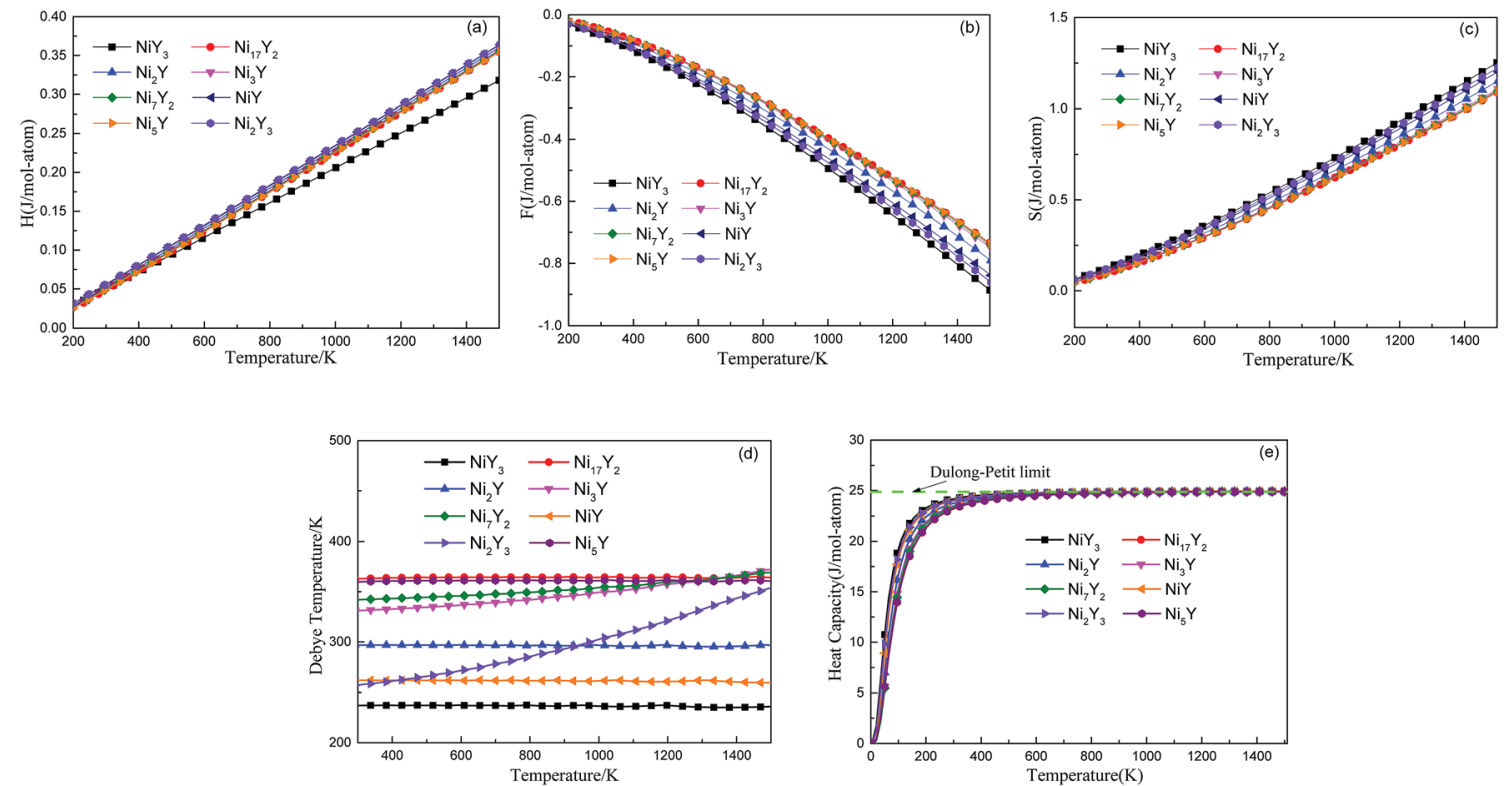

Fig. 5 The predicted vibration contribution to thermodynamics of $\mathrm{Ni}-\mathrm{Y}$ compounds from phonon as a function of temperature: (a) enthalpy; (b) Helmholtz free energy; (c) entropy; (d) Debye temperature; (e) the isochoric heat capacity of Ni-Y compounds. 
Table 2 The calculated independent elastic constants $\left(C_{i j}\right)$ of $\mathrm{Ni}-\mathrm{Y}$ compounds and the units are GPa

\begin{tabular}{|c|c|c|c|c|c|c|c|c|c|c|c|c|c|c|c|c|c|c|c|}
\hline Species & $C_{11}$ & $C_{22}$ & $C_{33}$ & $C_{44}$ & $C_{55}$ & $C_{66}$ & $C_{12}$ & $C_{13}$ & $C_{14}$ & $C_{15}$ & $C_{16}$ & $C_{23}$ & $C_{24}$ & $C_{25}$ & $C_{26}$ & $C_{34}$ & $C_{35}$ & $C_{36}$ & $C_{46}$ \\
\hline $\mathrm{Ni}$ & 248.63 & & & 114.24 & & & 171.59 & & & & & & & & & & & & \\
\hline $\mathrm{Y}$ & 31.07 & & & 13.50 & & & 47.18 & & & & & & & & & & & & \\
\hline $\mathrm{Ni}_{5} \mathrm{Y}$ & 298.92 & & 294.31 & 79.85 & & & 158.37 & 107.85 & & & & & & & & & & & \\
\hline $\mathrm{Ni}_{7} \mathrm{Y}_{2}$ & 226.83 & 213.27 & 229.38 & 64.74 & 64.64 & 60.28 & 100.05 & 97.55 & 8.09 & -2.06 & -0.34 & 93.73 & 8.09 & -10.46 & -0.9 & 7.95 & -5.98 & -1.68 & -4.26 \\
\hline $\mathrm{Ni}_{3} \mathrm{Y}$ & 232.91 & 225.83 & 233.76 & 63.72 & 63.72 & 64.81 & 99.72 & 94.51 & 0.24 & 7.62 & 4.68 & 90.51 & 0.23 & -3.99 & 4.64 & 0.16 & 2.11 & 5.09 & -5.79 \\
\hline $\mathrm{Ni}_{2} \mathrm{Y}_{3}$ & 120.48 & & 67.99 & 27.35 & & 33.25 & 71.21 & 68.17 & & & & & & & & & & & \\
\hline $\mathrm{NiY}_{3}$ & 105.70 & 71.15 & 96.90 & 21.18 & 29.65 & 31.66 & 34.54 & 45.99 & & & & 32.51 & & & & & & & \\
\hline
\end{tabular}

direction. In Table 2 , the value of $\mathrm{Ni}_{5} \mathrm{Y}$ is $298.92 \mathrm{GPa}$ which is larger than other $\mathrm{Ni}-\mathrm{Y}$ compounds, indicating that $\mathrm{Ni}_{5} \mathrm{Y}$ is hard to be compressed under the external uniaxial stress along [100] direction. It has the largest $C_{44}$ value is $79.85 \mathrm{GPa}$ at (100) plane. While $\mathrm{NiY}_{3}$ has the smallest values of $C_{12}$ that indicate a strong shear deformation. The values of $C_{11}$ change from 105 GPa up to $298 \mathrm{GPa}$.

There are eight crystal structure types of the $\mathrm{Ni}-\mathrm{Y}$ compounds which including cubic, tetragonal, rhombohedral, hexagonal, and orthorhombic. As shown in Tables 1 and 2, NiY and $\mathrm{NiY}_{3}$ are the orthorhombic types, which has 9 independent elastic stiffness tensor elements. $\mathrm{Ni}_{2} \mathrm{Y}$ has a cubic structure with 3 independent elastic stiffness tensor elements. $\mathrm{Ni}_{7} \mathrm{Y}_{2}$ and $\mathrm{Ni}_{3} \mathrm{Y}$ are the rhombohedral structure, $\mathrm{Ni}_{2} \mathrm{Y}_{3}$ is the tetragonal type with 6 independent elastic stiffness tensor elements. As for $\mathrm{Ni}_{5} \mathrm{Y}$ and $\mathrm{Ni}_{17} \mathrm{Y}_{2}$, there are 5 independent elastic stiffness tensor elements.

Based on these calculated elastic stiffness tensor of $\mathrm{Ni}-\mathrm{Y}$ compounds and according to the mechanical stability criteria. ${ }^{27}$ The formulas of elastic moduli and mechanical stability criteria for the considered crystal systems are introduced. The condition $C_{12}<B<C_{11}$ is used in order to study the hardness of a material. The elastic constants obey the mechanical stability conditions based on the Born Standard ${ }^{28}$ for a different structure.

The bulk modulus and shear modulus of Ni-Y compounds are computed according to the Voigt-Reuss-Hill (VRH) approximation. $^{29}$ Therefore, Young's modulus and Poisson's

Table 3 The calculated bulk modulus $(B)$, shear modulus $(G)$, Young's modulus $(E), B / G$, and Poisson's ratio $(\nu)$ and Vickers hardness $(G P a)$ of $\mathrm{Ni}-\mathrm{Y}$ compounds and the units are $\mathrm{GPa}$

\begin{tabular}{|c|c|c|c|c|c|c|c|c|c|}
\hline species & $B$ & $G$ & $E$ & $\nu$ & $B / G$ & $H_{\mathrm{v}}$ & $A^{\mathrm{U}}$ & $A_{\mathrm{B}}$ & $A_{\mathrm{G}}$ \\
\hline $\mathrm{Ni}_{17} \mathrm{Y}_{2}$ & 172.1 & 79.13 & 205.85 & 0.30 & 2.18 & 7.39 & 0.079 & 0 & 0.008 \\
\hline $\mathrm{Ni}_{5} \mathrm{Y}$ & 181.71 & 79.75 & 208.70 & 0.31 & 2.27 & 6.89 & 0.106 & 0.003 & 0.010 \\
\hline $\mathrm{Ni}_{7} \mathrm{Y}_{2}$ & 138.23 & 62.89 & 163.83 & 0.30 & 2.20 & 5.98 & 0.535 & 0.006 & 0.004 \\
\hline $\mathrm{Ni}_{3} \mathrm{Y}$ & 139.99 & 65.34 & 169.63 & 0.30 & 2.14 & 6.46 & 0.049 & 0.002 & 0.004 \\
\hline $\mathrm{Ni}_{2} \mathrm{Y}$ & 144.08 & 55.99 & 148.71 & 0.33 & 2.57 & 3.97 & 0.127 & 0 & 0.013 \\
\hline $\mathrm{NiY}$ & 79.01 & 32.82 & 86.49 & 0.32 & 2.41 & 2.52 & 0.534 & 0.070 & 0.037 \\
\hline $\mathrm{Ni}_{2} \mathrm{Y}_{3}$ & 74.22 & 21.33 & 58.41 & 0.37 & 3.48 & 0.21 & 1.829 & 0.083 & 0.141 \\
\hline $\mathrm{NiY}_{3}$ & 54.20 & 26.82 & 69.06 & 0.29 & 2.02 & 3.01 & 0.201 & 2.248 & 0.015 \\
\hline
\end{tabular}

ratios are obtained by the relationships between bulk modulus and shear modulus. ${ }^{30,31}$

$$
\begin{gathered}
E=9 B G /(3 B / G) \\
\nu=(3 B-2 G) /(6 B+2 G)
\end{gathered}
$$

The results of $B, G, E$ and $\nu$ of Ni-Y compounds are listed in Table 3. What's more, from Fig. 6(a), with the Y concentration increasing, the trend of shear modulus of $\mathrm{Ni}-\mathrm{Y}$ compounds is similar to Young's modulus and Bulk modulus. The calculated
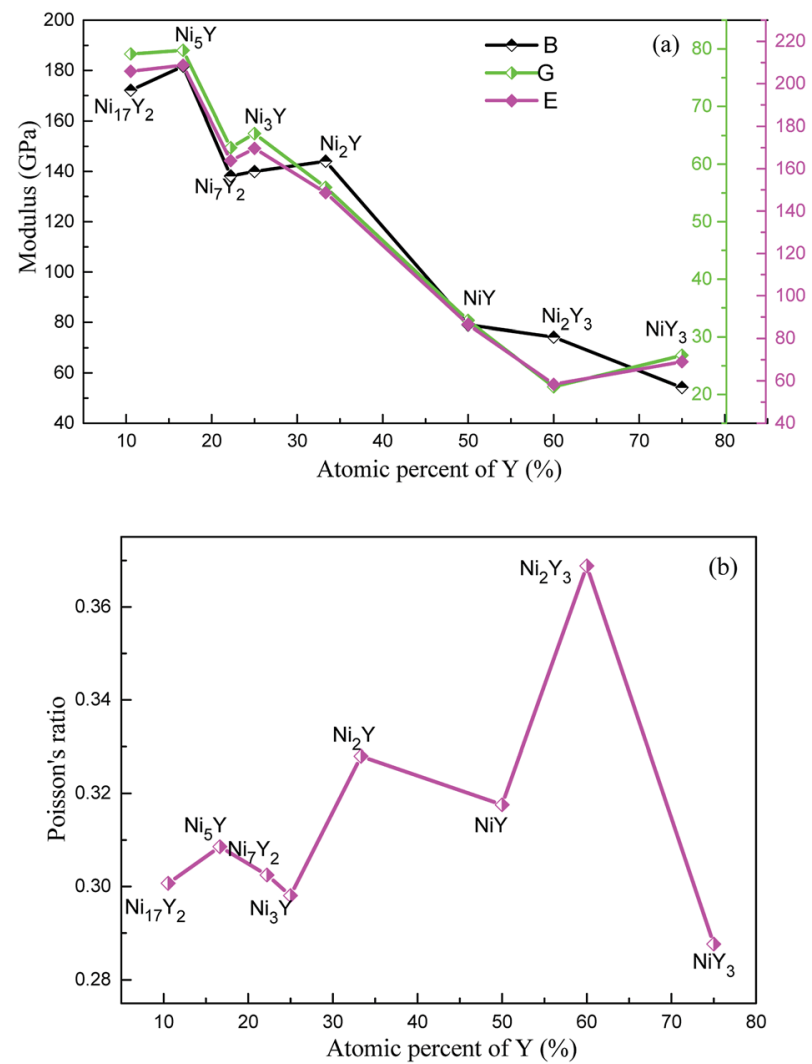

Fig. 6 (a) The calculated bulk modulus (B), shear modulus ( $G$ ) and Young's modulus $(E)$ of $\mathrm{Ni}-\mathrm{Y}$ compounds as a function of $Y$ concentration, (b) the Poisson's ratio $(\nu)$ of $\mathrm{Ni}-\mathrm{Y}$ compounds as a function of $Y$ concentration. 


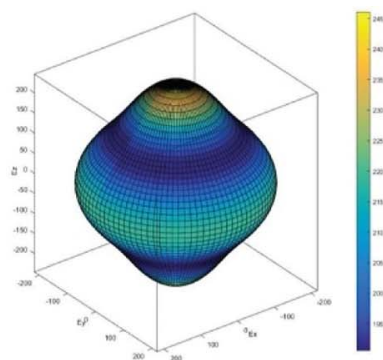

(a)

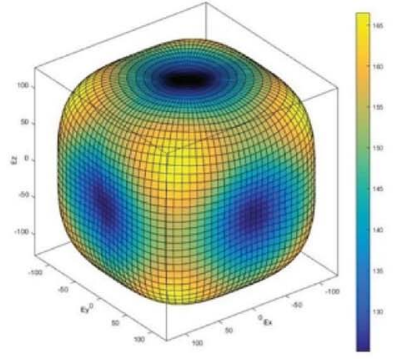

(e)

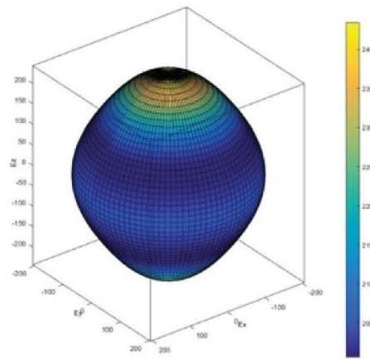

(b)

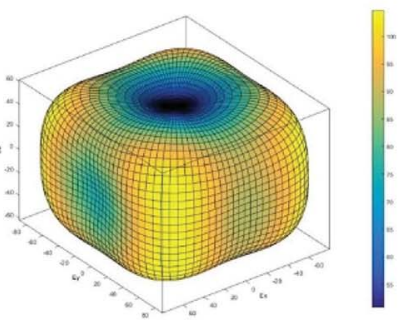

(f)

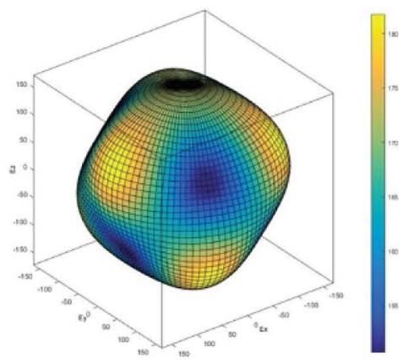

(c)

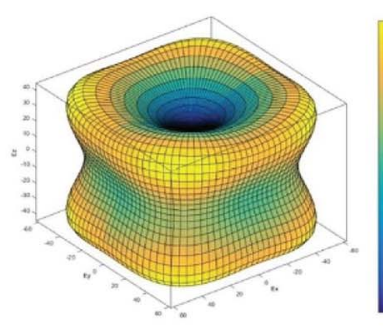

(g)

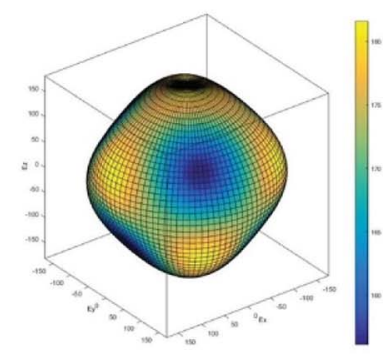

(d)

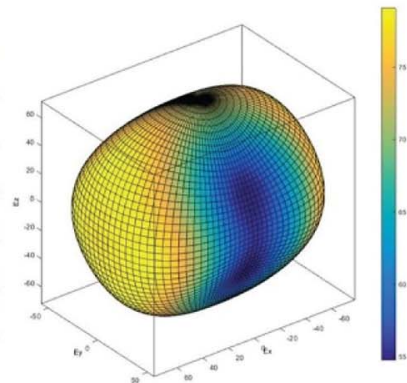

(h)

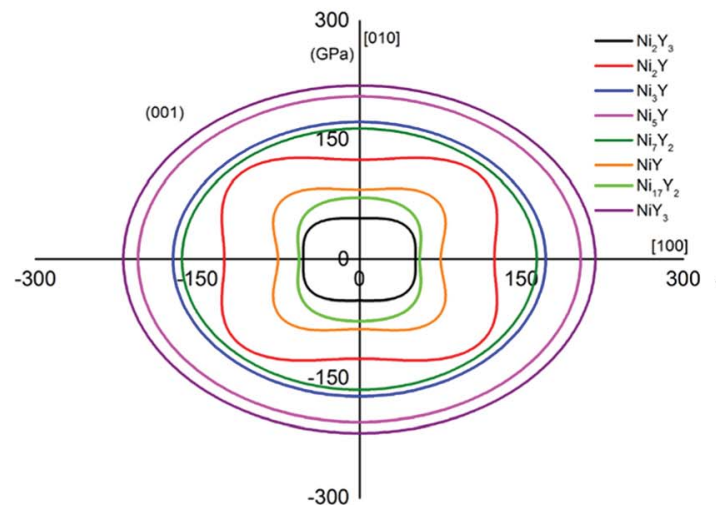

(i) the (001) plane

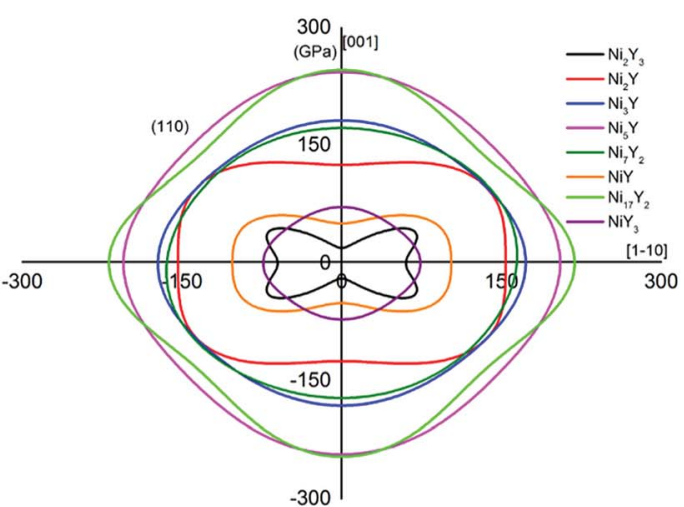

(j) the (110) plane

Fig. 7 (a-h) (a) $\mathrm{Ni}_{17} \mathrm{Y}_{2}$, (b) $\mathrm{Ni}_{5} \mathrm{Y}$, (c) $\mathrm{Ni}_{7} \mathrm{Y}_{2}$, (d) $\mathrm{Ni}_{3} \mathrm{Y}$, (e) $\mathrm{Ni}_{2} \mathrm{Y}$, (f) NiY, (g) Ni $\mathrm{N}_{3}$, (h) NiY, The surface contours of the Young's modulus of Ni-Y compounds. (i and j) The (001) and (110) plane projections of $\mathrm{Ni}-\mathrm{Y}$ compounds.

shear modulus of Ni-Y compounds decreases with the increase of $\mathrm{Y}$ concentration except for $\mathrm{Ni}_{3} \mathrm{Y}$ and $\mathrm{NiY}_{3}$. Therefore, the variation of shear modulus is related to the $\mathrm{Y}$ concentration and chemical bonds which includes the bonding type and orientation of bond. The values of bulk modulus and Young's modulus are changed from $60 \mathrm{GPa}$ up to $200 \mathrm{GPa}$. The obtained bulk modulus, shear modulus and Young's modulus of $\mathrm{Ni}_{5} \mathrm{Y}$ are 181.71 GPa, 79.75 GPa, and 208.7 GPa, respectively, which are larger than that of other Ni-Y compounds. The ductile or brittle of materials can be determined by the $B / G$ ratio and Poisson's ratio. Furthermore, the degree of orientation of chemical bonds is controlled by the Poisson's ratio. ${ }^{32}$ The Poisson's ratio of Ni-Y compounds as a function of $\mathrm{Y}$ concentration is shown in Fig. 6(b). For this purpose, Pugh's criteria ${ }^{33}$ is used. According to this criteria, a compound is ductile when $B / G>1.75$, otherwise brittle if $B / G<1.75$. From Table 3 analysis, the value $B / G>1.75$ in $\mathrm{Ni}-\mathrm{Y}$ systems, so all the $\mathrm{Ni}-\mathrm{Y}$ compounds show ductile behavior. The calculated elastic constants $C_{i j}$ of $\mathrm{Ni}-\mathrm{Y}$ compounds are summarized in Table 2. The mechanical stability of a crystal implies that the strain energy must be positive, then the determinants of the matrices of the principal minors of $C_{i j}$ matrix should be all positive. ${ }^{34}$ We can analyze the mechanical stability of those compounds in Table 3 . The $B / G$ value of all $\mathrm{Ni}-\mathrm{Y}$ compounds being larger than 1.75 indicates the ductility of these phases. Among them, $\mathrm{Ni}_{2} \mathrm{Y}_{3}$ bears the largest $B / G$ value of 3.48 , revealing the excellent ductility of this compounds. While the $B / G$ value of others compounds is bigger than 1.75 , but no more than 3 . Most of the Ni-Y compounds have a high bulk modulus, indicating that they are not easy to be compressed. What's more, the calculated Poisson's ratio of $\mathrm{Ni}-\mathrm{Y}$ compounds is close to 0.3 , suggesting they have stronger metallic bonding. We all know that the value of the bulk 

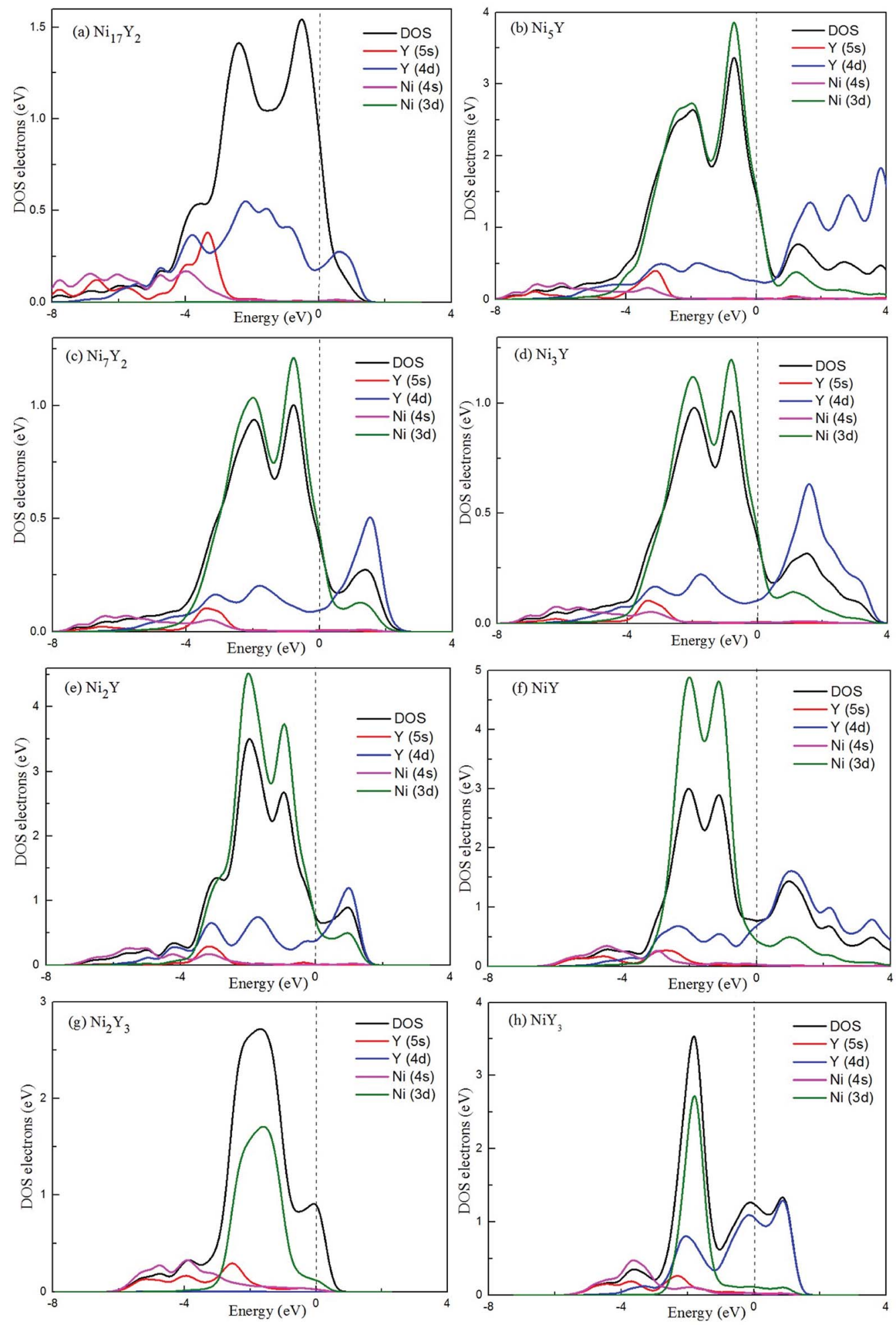

Fig. 8 The total density of state (TDOS) and partial density of state (PDOS) for Ni-Y compounds, the dashed line represents the Fermi energy.

modulus is not only related to the atomic radius, but also to the crystal structure.

The anisotropy of Ni-Y compounds can be described through the universal anisotropic index $\left(A^{\mathrm{U}}\right)$ and percent anisotropic index $\left(A_{\mathrm{B}}\right.$ and $\left.A_{\mathrm{G}}\right)$ according to following formula: ${ }^{35}$

$$
\begin{gathered}
A^{\mathrm{U}}=5 \frac{G_{\mathrm{V}}}{G_{\mathrm{R}}}+\frac{B_{\mathrm{V}}}{B_{\mathrm{R}}}-6 \geq 0 \\
A_{\mathrm{B}}=\frac{B_{\mathrm{V}}-B_{\mathrm{R}}}{B_{\mathrm{V}}+B_{\mathrm{R}}}
\end{gathered}
$$



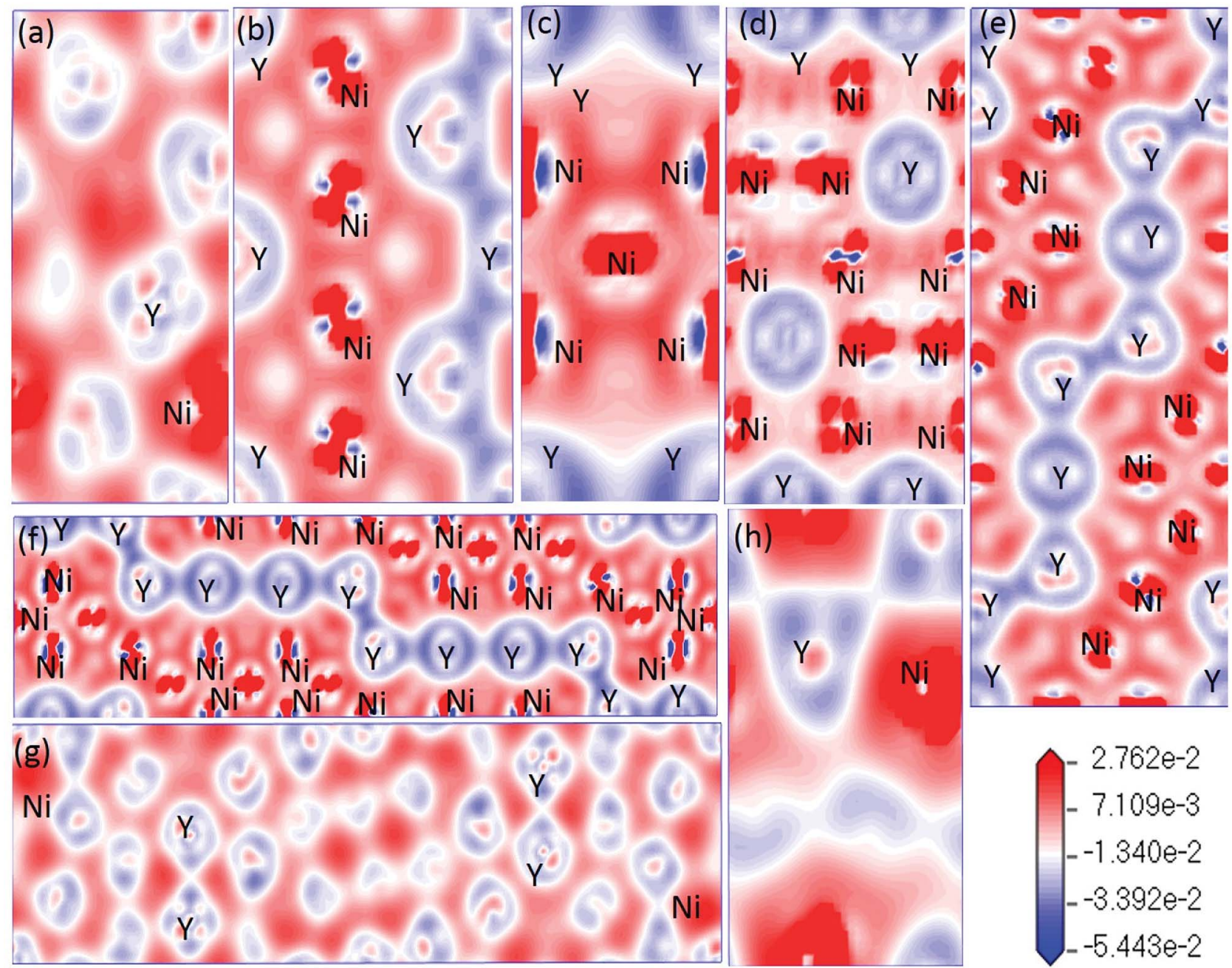

Fig. 9 (a-h) (a) NiY, (b) $\mathrm{Ni}_{2} \mathrm{Y}$, (c) $\mathrm{Ni}_{5} \mathrm{Y}$, (d) $\mathrm{Ni}_{17} \mathrm{Y}_{2}$, (e) $\mathrm{Ni}_{3} \mathrm{Y}$, (f) $\mathrm{Ni}_{7} \mathrm{Y}_{2}$, (g) $\mathrm{Ni}_{2} \mathrm{Y}_{3}$, (h) NiY. The differences of charge density distribution for stable Ni-Y compounds in the (110) plane.

$$
A_{\mathrm{G}}=\frac{G_{\mathrm{V}}-G_{\mathrm{R}}}{G_{\mathrm{V}}+G_{\mathrm{R}}}
$$

where $B_{\mathrm{V}}, B_{\mathrm{R}}, G_{\mathrm{V}}$ and $G_{\mathrm{R}}$ represent the bulk modulus and share modulus estimation within Voigt and Reuss approximations, respectively.

The value of the anisotropy index is close to zero, and the greater the deviation from zero indicates the more anisotropy of the material. The results are listed in Table $3 . \mathrm{Ni}_{2} \mathrm{Y}_{3}$ has the highest values of the $A^{\mathrm{U}}$, indicating that the elastic properties of $\mathrm{Ni}_{2} \mathrm{Y}_{3}$ in Ni-Y compounds have the strongest anisotropy. Similarly, the value of $A_{\mathrm{G}}, A_{\mathrm{B}}$ also confirmed the results. $\mathrm{Ni}_{2} \mathrm{Y}_{3}$ has the largest values 0.141 of the $A_{\mathrm{G}}$, representing that the anisotropy of bulk modulus is weak. What's more, the threedimensional (3D) surface contour offers a more detailed and visual elastic anisotropy. For the hexagonal structure in any directions was given by ref. 36 .

$$
\frac{1}{E}=\left(1-l_{3}{ }^{2}\right)^{2} S_{11}-l_{3}^{4} S_{33}+l_{3}{ }^{2}\left(1-l_{3}{ }^{2}\right)\left(2 S_{13}+S_{44}\right)
$$

For monoclinic structure:

$$
\begin{aligned}
\frac{1}{E}= & l_{1}{ }^{4} S_{11}+l_{2}{ }^{4} S_{22}+l_{3}{ }^{4} S_{33}+2 l_{1}{ }^{2} l_{2}{ }^{2} S_{12}+2 l_{1}{ }^{2} l_{3}{ }^{2} S_{13}+2 l_{1}{ }^{3} l_{3} S_{15} \\
& +2 l_{2}{ }^{2} l_{3}{ }^{2} S_{23}+2 l_{1} l_{2}{ }^{2} l_{3} S_{25}+2 l_{1} l_{3}{ }^{3} S_{35}+l_{2}{ }^{2} l_{3}{ }^{2} S_{44}+2 l_{1} l_{2}{ }^{2} l_{3} S_{46} \\
& +l_{1}{ }^{2} l_{3}{ }^{2} S_{55}+l_{1}{ }^{2} l_{2}{ }^{2} S_{66}
\end{aligned}
$$

For orthorhombic structure:

$$
\begin{aligned}
\frac{1}{E}= & S_{11} l_{1}{ }^{4}+S_{22} l_{2}{ }^{4}+S_{33} l_{3}{ }^{4}+\left(2 S_{12}+S_{66}\right) l_{1}{ }^{2} l_{2}{ }^{2}+\left(2 S_{13}\right. \\
& \left.+S_{55}\right) l_{1}{ }^{2} l_{3}{ }^{2}+\left(2 S_{23}+S_{44}\right) l_{2}{ }^{2} l_{3}{ }^{2}
\end{aligned}
$$

Eqn (14) can be applied in the tetragonal and cubic structure. Where $S_{i j}$ is the usual elastic compliance constant, which is obtained from the inverse of the matrix of the elastic constants, and $l_{1}, l_{2}, l_{3}$ are the direction cosines. The result surface contours of Young's modulus for $\mathrm{Ni}-\mathrm{Y}$ compounds are illustrated in Fig. 7. We can see that Young's modulus of Ni-Y 
Table 4 Population analysis of Ni-Y compounds, the calculated average bond length $(\bar{L}(\mathrm{AB})(\AA \AA))$ and the mean bond population $(\bar{n}(\mathrm{AB})(\mathrm{e}))$ are shown

\begin{tabular}{|c|c|c|c|c|c|c|c|c|c|}
\hline \multirow[t]{5}{*}{$\mathrm{Ni}_{17} \mathrm{Y}_{2}$} & $\mathrm{Ni}_{1}$ & 0.68 & 0.53 & 8.72 & 9.92 & 0.08 & $\mathrm{Ni}-\mathrm{Y}$ & 2.91 & 0.22 \\
\hline & $\mathrm{Ni}_{2}$ & 0.61 & 0.45 & 8.72 & 9.78 & 0.22 & $\mathrm{Ni}-\mathrm{Ni}$ & 2.39 & 0.11 \\
\hline & $\mathrm{Ni}_{4}$ & 0.49 & 0.36 & 8.73 & 9.59 & 0.41 & & & \\
\hline & $\mathrm{Y}_{1}$ & 0.58 & 2.15 & 1.85 & 4.59 & -1.59 & & & \\
\hline & $\mathrm{Y}_{2}$ & 0.57 & 1.85 & 1.81 & 4.23 & -1.23 & & & \\
\hline & $\mathrm{Y}$ & 0.54 & 1.37 & 1.84 & 3.75 & -0.75 & & & \\
\hline \multirow[t]{5}{*}{$\mathrm{Ni}_{7} \mathrm{Y}_{2}$} & $\mathrm{Ni}_{1}$ & 0.63 & 0.27 & 8.74 & 9.64 & 0.36 & $\mathrm{Ni}-\mathrm{Y}$ & 2.92 & 0.45 \\
\hline & $\mathrm{Ni}_{2}$ & 0.64 & 0.27 & 8.75 & 9.65 & 0.35 & $\mathrm{Ni}-\mathrm{Ni}$ & 2.55 & 0.12 \\
\hline & $\mathrm{Ni}_{3}$ & 0.79 & 0.54 & 8.77 & 10.11 & -0.11 & & & \\
\hline & $\mathrm{Ni}_{4}$ & 0.75 & 0.46 & 8.72 & 9.93 & 0.07 & & & \\
\hline & $\mathrm{Ni}_{5}$ & 0.76 & 0.50 & 8.74 & 10.00 & 0 & & & \\
\hline & $\mathrm{Ni}_{3}$ & 0.75 & 0.50 & 8.74 & 9.99 & 0.01 & & & \\
\hline & $\mathrm{Y}_{1}$ & 0.38 & 0.82 & 1.97 & 3.18 & -0.18 & & & \\
\hline & $\mathrm{Y}_{2}$ & 0.45 & 1.12 & 1.81 & 3.38 & -0.38 & & & \\
\hline \multirow[t]{2}{*}{$\mathrm{Ni}_{2} \mathrm{Y}$} & $\mathrm{Ni}$ & 0.74 & 0.54 & 8.77 & 10.05 & -0.05 & $\mathrm{Ni}-\mathrm{Ni}$ & 2.59 & 0.14 \\
\hline & $\mathrm{Y}$ & 0.3 & 0.63 & 1.97 & 2.9 & 0.1 & & & \\
\hline \multirow[t]{2}{*}{$\mathrm{NiY}$} & $\mathrm{Ni}$ & 0.86 & 0.27 & 8.83 & 9.96 & 0.04 & $\mathrm{Ni}-\mathrm{Y}$ & 2.96 & 0.28 \\
\hline & $\mathrm{Y}$ & 0.64 & 0.54 & 1.86 & 3.04 & -0.04 & $\mathrm{Ni}-\mathrm{Ni}$ & 2.48 & 0.22 \\
\hline \multirow[t]{5}{*}{$\mathrm{Ni}_{2} \mathrm{Y}_{3}$} & $\mathrm{Ni}_{1}$ & 0.85 & 0.25 & 8.84 & 9.94 & 0.06 & $\mathrm{Ni}-\mathrm{Y}$ & 2.95 & 0.29 \\
\hline & $\mathrm{Ni}_{2}$ & 0.83 & 0.33 & 8.85 & 10.01 & -0.01 & $\mathrm{Ni}-\mathrm{Ni}$ & 2.53 & 0.11 \\
\hline & $\mathrm{Ni}_{3}$ & 0.84 & 0.36 & 8.85 & 10.05 & -0.05 & & & \\
\hline & $\mathrm{Ni}_{4}$ & 0.84 & 0.22 & 8.84 & 9.91 & 0.09 & & & \\
\hline & $\mathrm{Y}_{1}$ & 0.66 & 0.49 & 1.86 & 3.01 & -0.01 & & & \\
\hline & $\mathrm{Y}_{2}$ & 0.61 & 0.47 & 1.91 & 3.00 & 0.00 & & & \\
\hline
\end{tabular}

compounds have different surface construction due to they have a different crystal structure, the shape of planar contours and size of Ni-Y compounds are also different. The 3D directional dependence of a solid with a spherical shape suggests isotropic. While the deviation degree of spherical shape has a certain response to the degree of anisotropy, and more deviation means more elastic anisotropy. The strong anisotropy of Young's modulus for Ni-Y compounds are shown by deviating from the normal ellipse at (001) and (110) plane. We can see that all compounds possess anisotropy from Fig. 7. It is obvious that the planar contours of the $\mathrm{Ni}_{5} \mathrm{Y}$ have the maximum Young's modulus along the axes on (001) and (110) plane. $\mathrm{NiY}$ and $\mathrm{Ni}_{2} \mathrm{Y}$ have the same planar contours on (001) and (110) plane while the value is different.

In addition, the theoretical hardness of $\mathrm{Ni}-\mathrm{Y}$ compounds can be calculated according to the semiempirical hard model.

$$
H_{\mathrm{v}}=2 \times\left(k^{2} \times G\right)^{0.585}-3
$$

where $k$ represents the $B / G$ ratio and $G$ is the shear modulus. The results Ni-Y compounds are shown in Table 3. The hardness of Ni-Y compound gradually decreases with the increase of Y element concentration except for the $\mathrm{Ni}_{2} \mathrm{Y}_{3}$ and $\mathrm{NiY}_{3}$. The $\mathrm{Ni}_{5} \mathrm{Y}$ has the largest hardness as $6.89 \mathrm{GPa}$ while $\mathrm{Ni}_{2} \mathrm{Y}_{3}$ has the smallest value with $0.21 \mathrm{GPa}$ due to different atomic constitute and disparate crystal types. The similar phenomenon can be observed between shear modulus and bulk modulus in those compounds. From the above discussion, we can get a result that these compounds are not potential superhard materials.

\subsection{Electronic structure}

To our knowledge, a density of states can be used as a visual result of band structure. A lot of analysis has common ground with energy band analysis, and many terms of density of states are interlinked with band analysis. It's much broader in the outcome discussion than the band analysis because it's more intuitive. Electron charge density shows the bonding nature of 

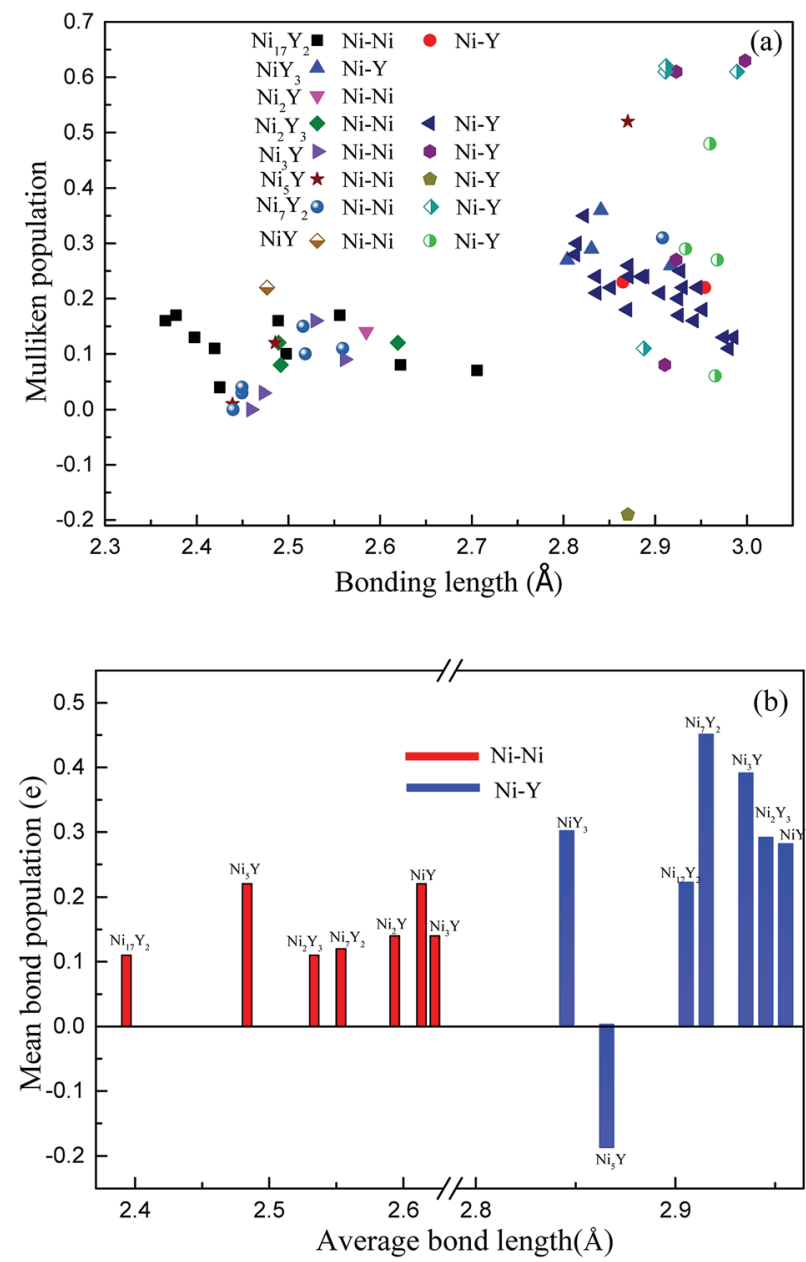

Fig. 10 (a) The calculated Mulliken's overlap population of $\mathrm{Ni}-\mathrm{Y}$ compounds; (b) the mean bond population of $\mathrm{Ni}-\mathrm{Y}$ compounds.

the compound whether it is ionic or covalent. The total density of state (TDOS) and partial density of state (PDOS) for Ni-Y compounds are shown as Fig. 8, and the dashed line represents the Fermi level $\left(E_{\mathrm{F}}\right)$. It is clear that some bands are across the $E_{\mathrm{F}}$, indicating that those Ni-Y compounds exhibit metallic behavior. It is noted that the DOS profiles of those Ni-Y compounds are contributed by the Ni-4d state, Ni-5s state, Y-3d state and Y-4s state. The strong hybridization between the $\mathrm{Ni}$ atom and the $\mathrm{Y}$ atom forms the strong $\mathrm{Ni}-\mathrm{Y}$ bonds along the $\mathrm{d}-$ d directions.

In Fig. 8, the low-energy part of the DOS consists mainly of $N_{\mathrm{Ni}}(\varepsilon)$ and the high-energy part consists of $N_{\mathrm{Y}}(\varepsilon)$. Because of the $3 \mathrm{~d}-4 \mathrm{~d}$ hybridization, it is not zero even in the high-energy region. These facts are seen in the calculated DOS by M. Shimizu et al. ${ }^{3}$ Obviously, the bandwidth of $\mathrm{Ni}_{5} \mathrm{Y}$ is the range from -8 up to 12 , which is larger than that of other Ni-Y compounds. These results are attributed to the overlap of the wave functions between the $\mathrm{Y}$ atoms increases. It is clear that $\mathrm{Ni}-\mathrm{Y}$ compounds are the metallic character due to the finite value of the DOS at Fermi level $\left(E_{\mathrm{F}}\right)$. According to the lower the $N\left(E_{\mathrm{F}}\right)$ is, the better the stability of the DOS at the Fermi level..$^{37}$ The value of $\mathrm{Ni}_{2} \mathrm{Y}_{3}$ near Fermi energy level is higher than other compounds, indicating that $\mathrm{Ni}_{2} \mathrm{Y}_{3}$ is less stable, which accords with analysis on the formation enthalpy in Fig. 4. What's more, the different concentration of $\mathrm{Y}$ affects the localized hybridization and chemical bonding between $\mathrm{Ni}$ atoms and $\mathrm{Y}$ atoms. To further gain some insight into the correlation between the mechanical properties and chemical bonding, Fig. 9 shows the contours of electron density difference of $\mathrm{Ni}-\mathrm{Y}$ compounds. The blue region represents the accumulation of electronic charge. The red region is consistent with the depletion of electronic charge. It further indicates that Ni-Y metallic bonds are observed in these compounds, which accords with analysis on the TDOS and PDOS in Fig. 8. For Ni-Y compounds, the depletion of electronic charge is obvious between $\mathrm{Ni}-\mathrm{Ni}$ and $\mathrm{Y}-\mathrm{Y}$, while is weaker among $\mathrm{Ni}$ atoms and $\mathrm{Y}$ atoms. All of the valence electron density show symmetry except for the $\mathrm{NiY}$ and $\mathrm{Ni}_{2} \mathrm{Y}$. The strong electron delocalization occurs in the $\mathrm{Ni}-\mathrm{Y}$ lattice, and the electron is distributed through the matrix map, indicating the metal bond interaction between the metal atoms.

What's more, some quantitative information for the transferred charge of the Ni-Y compounds are shown in Table 4 . The bond length and the population value of the chemical bond are calculated, according to following equation, ${ }^{38}$ we can get the average bond length and the average bond population.

$$
\begin{gathered}
\bar{L}(A B)=\frac{\sum_{\mathrm{i}} L_{\mathrm{i}} N_{\mathrm{i}}}{\sum_{\mathrm{i}} N_{\mathrm{i}}} \\
\bar{n}(A B)=\frac{\sum_{\mathrm{i}} n_{\mathrm{i}}^{A B} N_{\mathrm{i}}}{\sum_{\mathrm{i}} N_{\mathrm{i}}}
\end{gathered}
$$

where $\bar{L}(\mathrm{AB})$ and $\bar{n}(\mathrm{AB})$ express the average bond length and the mean bond population, respectively. In the cell, $N_{\mathrm{i}}$ is the total number of $i$ bond and $L_{\mathrm{i}}$ is the bond length of $\mathrm{i}$ type. From the Table 4 and Fig. 10(a), the positive charges carried by Ni atoms vary from 0.01 to 0.36 electrons, while the negative charges is from -0.01 to -0.11 electrons. But for $\mathrm{Y}$ atoms, the positive charges is in the range 0.01 to 0.1 electrons, and the negative charges are in the range -0.01 to -0.75 electrons. In Fig. 10 (b), we can know that the value of an average length of $\mathrm{Ni}-\mathrm{Y}$ is about $2.9 \AA$, so their ionicity is roughly the same. However, the ionicity of $\mathrm{Ni}_{2} \mathrm{Y}_{3}$ is slightly stronger than the other compounds, while the shortest $\mathrm{Ni}-\mathrm{Y}$ is $\mathrm{Ni}_{5} \mathrm{Y}$, as $2.87 \AA$, the similar trend can be obtained from Fig. 7. From Fig. 10(b), it is clear that the Ni-Ni bonding is shorter than the Ni-Y bonding. As everyone knows the bond population is proportional to the strength of the bonding. The bond population of $\mathrm{Ni}_{7} \mathrm{Y}_{2}$ is larger than the other compounds in Ni-Y alloys. So, it is the stronger chemical bonding. From Table $4, \mathrm{Ni}_{7} \mathrm{Y}_{2}$ and $\mathrm{Ni}_{3} \mathrm{Y}$ have not only the $\mathrm{Ni}-\mathrm{Y}$ strong metallic character but also the covalent as the bond population is greater than 0.35 .

\section{Conclusion}

In summary, the stability, elastic properties, mechanical properties and electronic structures of the $\mathrm{Ni}_{17} \mathrm{Y}_{2}, \mathrm{Ni}_{5} \mathrm{Y}, \mathrm{Ni}_{7} \mathrm{Y}_{2}, \mathrm{Ni}_{3} \mathrm{Y}$, $\mathrm{Ni}_{2} \mathrm{Y}, \mathrm{NiY}, \mathrm{Ni}_{2} \mathrm{Y}_{3}$ and $\mathrm{NiY}_{3}$ in the $\mathrm{Ni}-\mathrm{Y}$ system are assessed in detail via first principle calculations in the present work. Firstly, we discuss the thermodynamic properties of Ni-Y compounds in detail. The calculated phonon distribution curves of $\mathrm{Ni}-\mathrm{Y}$ 
compounds have no soft mode, indicating that all compounds are thermodynamic stability. The elastic stiffness tensors and properties of these $\mathrm{Ni}-\mathrm{Y}$ compounds including bulk modulus, shear modulus, Young's modulus, and Poisson's ratio are calculated. With the lower the enthalpy of formation is, the more stable the compounds are. The stability of these compounds forms the following sequence: $\mathrm{NiY}>\mathrm{Ni}_{2} \mathrm{Y}>\mathrm{Ni}_{3} \mathrm{Y}>$ $\mathrm{Ni}_{7} \mathrm{Y}_{2}>\mathrm{Ni}_{5} \mathrm{Y}>\mathrm{Ni}_{2} \mathrm{Y}_{3}>\mathrm{Ni}_{17} \mathrm{Y}_{2}>\mathrm{NiY}_{3}$ in the Ni-Y compounds. All $\mathrm{Ni}-\mathrm{Y}$ compounds have a high bulk modulus, indicating that they are difficult to be compressed. $\mathrm{Ni}_{5} \mathrm{Y}$ has the largest bulk modulus which the value is $181.71 \mathrm{GPa}$. We also analyze the different bulk modulus value of $\mathrm{Ni}-\mathrm{Y}$ compounds due to the different $\mathrm{Y}$ content and various crystal structures. Based on the analysis of the electronic structure, $\mathrm{Ni}_{7} \mathrm{Y}_{2}$ and $\mathrm{Ni}_{3} \mathrm{Y}$ have not only the Ni-Y strong metallic character but also the covalent as the bond population is greater than 0.35 , thus showing very strong mechanical properties. And this work would be significant for understanding the further application of $\mathrm{Ni}-\mathrm{Y}$ compounds in the future.

\section{Conflicts of interest}

There are no conflicts to declare.

\section{Acknowledgements}

This work was supported by Key Project of Science \& Technology in Yunnan Province, (No. 2018ZE019) and Yunnan Education Department Scientific Research Fund Project, (No. 2017ZZX134) and Kunming University of Science and Technology Natural Science Research Fund Project (Provincial People Training Project) (No. KKSY201651036).

\section{References}

1 B. J. Beaudry and A. H. Daane, Trans. Metall. Soc. AIME, 1960, 218, 854.

2 A. G. Kuchin, V. P. Glazkov, D. P. Kozlenko and B. N. Savenko, Binary ordered alloys and intermetallic compounds, Springer-Verlag, Berlin Heidelberg, 2014, vol. 162, pp. 138-139.

3 M. Shimizu, J. Inoue and S. Nagasawat, J. Phys. F: Met. Phys., 1984, 2673-2687.

4 P. Villars and K. Cenzual, Pearson's crystal data - crystal structure database for inorganic compounds (on CD-ROM), ASM International, Materials Park, OH, 2009, pp. 681-682.

5 R. Lemaire and D. Paccard, Bull. Soc. Fr. Mineral. Cristallogr., 1969, 92, 9.

6 X. Y. Jiang, Z. C. Zhong and A. L. Greer, Mater. Sci. Eng., A, 1997, 226-228, 789-793.

7 Y. M. Soifer, N. P. Kobelev, L. G. Brodova, A. N. Mannkhin and E. Korin, Nanostruct. Mater., 1999, 12, 875-878.

8 J. Beille, D. Gifnoux, R. Lemaire, M. Shimizu and J. Voiron, Phys., 1983, 119B, 133-141.

9 Z. M. Du and D. X. Lu, Intermetallics, 2005, 13, 586-595.

10 Z. M. Du and W. J. Zhang, J. Alloys Compd., 1996, 245, 164167.
11 Z. M. El-Bahy, Appl. Catal., A, 2013, 468, 175-183.

12 H. Xia, F. Drymiotis, C. L. Chen, A. Wu and G. J. Snyder, J. Mater. Sci., 2014, 1716-1723.

13 M. A. Shevchenko, M. I. Ivanov, V. V. Berezutskii, V. G. Kudin and V. S. Sudavtsova, Russ. J. Phys. Chem. A, 2014, 88, 897902.

14 S. Kardellass, C. Servan, N. Selhaoui, A. Iddaoudi, M. AitAmar and L. Bouirden, Calphad, 2013, 42, 59-65.

15 Y. J. Hu, Y. Wang, S. A. Firdosy, K. E. Star, J. P. Fleurial, V. A. Ravi and Z. K. Liu, Calphad, 2017, 59, 207-217.

16 N. Mattern, M. Zinkevich, W. Löser, G. Behr and J. Acker, J. Phase Equilib. Diffus., 2008, 29, 141-155.

17 M. D. Segall, P. J. D. Lindan, M. J. Probert, C. J. Pickard, P. J. Hasnip, S. J. Clark and M. C. Payne, J. Phys.: Condens. Matter, 2002, 14, 2717-2744.

18 J. P. Perdew, K. Burke and M. Ernzerhof, Phys. Rev. Lett., 1996, 77, 3865-3868.

19 D. Vanderbilt, Phys. Rev. B: Condens. Matter Mater. Phys., 1990, 41, 7892-7895.

20 M. Zhang, H. Wang, H. Wang, T. Cui and Y. Ma, J. Phys. Chem. C, 2010, 114, 6722-6725.

21 Q. Li, D. Zhou, W. Zheng, Y. Ma and C. Chen, Phys. Rev. Lett., 2013, 110, 136403.

22 J. D. Head and M. C. Zerner, Chem. Phys. Lett., 1985, 122, 264-270.

23 X. Y. Chong, Y. H. Jiang, R. Zhou and J. Feng, Ceram. Int., 2016, 42, 2117-2132.

24 S. Baroni, S. D. Gironcoli, A. D. Corso and P. Giannozzi, Rev. Mod. Phys., 2001, 73, 515-562.

25 X. Y. Chong, Y. H. Jiang, R. Zhou, H. Zhu and J. Feng, Comput. Mater. Sci., 2015, 108, 205-211.

26 J. J. Han, C. P. Wang, X. J. Liu, Y. Wang and Z. K. Liu, J. Phys.: Condens. Matter, 2012, 24, 505503.

27 G. Grimvall, Thermo physical properties of materials, Elsevier, 1999, vol. 39, pp. 273-297.

28 M. Born and K. Huang, Dynamical theory of crystal lattices, Clarendon Press, Oxford, 1954, vol. 141, p. 141.

29 R. W. Hill, Proc. Phys. Soc., 1952, 65, 349.

30 B. Xiao, J. Feng, C. T. Zhou, Y. H. Jiang and R. Zhou, J. Appl. Phys., 2011, 109, 083521.

31 X. L. Yuan, D. Q. Wei, X. R. Chen, Q. M. Zhang and Z. Z. Gong, J. Alloys Compd., 2011, 509, 769-774.

32 N. Korozlu, K. Colakoglu, E. Deligoz and S. Aydin, J. Alloys Compd., 2013, 546, 157-164.

33 S. F. Pugh, Philos. Mag., 1954, 45, 823-843.

34 F. Milstein, Phys. Rev. B: Condens. Matter Mater. Phys., 1971, 3, 1130.

35 S. I. Ranganathan and M. Ostojastarzewski, Phys. Rev. Lett., 2008, 101, 055504.

36 J. F. Nye, Hysical properties of crystals, Oxford University Press, Oxford, 1985.

37 W. Huang and Y. A. Chang, Intermetallics, 1998, 6, 487-498.

38 B. Xiao, J. D. Xing, J. Feng, C. T. Zhou, Y. F. Li, W. Su, X. J. Xie and Y. H. Cheng, J. Phys. D: Appl. Phys., 2009, 42, 115415. 